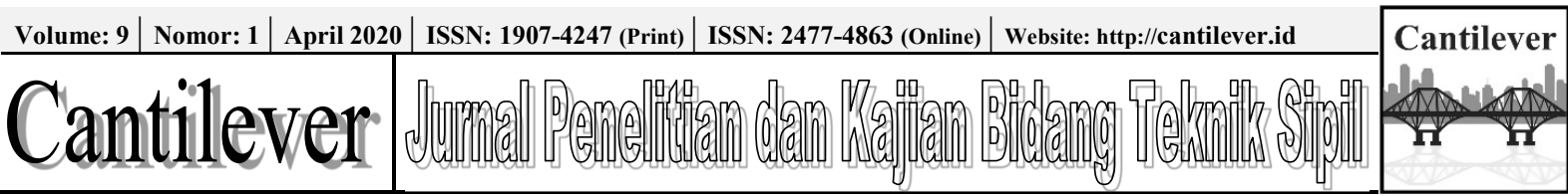

\title{
PENINGKATAN KAPASITAS TEMPAT PENAMPUNGAN SEMENTARA (TPS) CIROYOM MENJADI STASIUN PERALIHAN ANTARA (SPA) BERSKALA KAWASAN DI KECAMATAN ANDIR, KOTA BANDUNG
}

\author{
I Made Wahyu Widyarsana ${ }^{1)}$ dan Oloan Ivan Daniel ${ }^{2)}$ \\ ${ }^{1,2)}$ Program Studi Teknik Lingkungan, Fakultas Teknik Sipil dan Lingkungan, Institut Teknologi Bandung \\ Jl. Ganesha No. 10 Bandung 40132
}

\begin{abstract}
Ciroyom TPS is one of the waste facilities in Andir Sub-district. Ciroyom TPS is managed by PD Kebersihan Kota Bandung which works as temporary solid waste collection from residential and Ciroyom Market. The large area of the TPS Ciroyom service area, which is 5 out of 6 villages that produce large amounts of waste that reaches 45.43 tonnes/day. It makes the amount of waste transportation from TPS to TPA reach 12 ritation/day. The distance from TPS (Tempat Penampungan Sementara) Ciroyom to Sarimukti Regional Landfill which requires $44 \mathrm{~km}$ is a major consideration needed by the Waste Transfer Station (SPA, Stasiun Peralihan Antara) for regional scale. SPA takes in reducing the volume of waste so that it can reduce the ratio of garbage transportation to landfill (TPA, Tempat Pemrosesan Akhir). With adequate land area, TPS Ciroyom has the potential to improve its function to become SPA for regional scale. Through the analysis of several alternative concepts and development scenarios, the amount of waste generated will be managed at the SPA Ciroyom for the next 10 years. The main facilities designed at the SPA Ciroyom for regional scale are waste compaction units resulting in volume reduction with the vertical compression method. Through solidification of waste, residual waste classified as residues is expected to reduce the volume by $60-70 \%$. In addition, other facilities are provided which are designed at Ciroyom Area Scale SPA such as waste sorting facilities using conveyor belts, organic waste processing with open windrow systems, and inorganic waste recovery facilities that still have selling points.
\end{abstract}

Key Words: compaction, solid waste, transfer station, transportation, waste recovery.

\section{PENDAHULUAN}

Pengelolaan sampah di Indonesia masih menjadi permasalahan yang menjadi tantangan bagi pemerintah pusat maupun daerah sampai saat ini. UU No. 18 Tahun 2008 tentang Pengelolaan Sampah dan PP No. 81 Tahun 2012 tentang Pengelolaan Sampah Rumah Tangga dan Sampah Sejenis Sampah Rumah Tangga mengatur tentang mekanisme pengurangan dan penanganan sampah, penelitian ini mencakup kedua mekanisme pengelolaan tersebut. Pertambahan penduduk dan peningkatan aktivitas yang demikian pesat akibat perkembangan industri dan teknologi juga menjadi faktor utama meningkatnya jumlah sampah. Hal tersebut tentu memiliki dampak terutama bagi masyarakat yang tinggal di kota-kota besar berpenduduk padat. Pada tahun 2008 diperkirakan hanya sekitar $60 \%$ sampah di kota-kota besar di Indonesia yang dapat terangkut ke Tempat Pemrosesan Akhir (TPA) yang memiliki operasional utama berupa lahan-pengurukan (landfilling) (Damanhuri dkk., 2008 dan 2009).

Area yang menjadi fokus luaran dari penelitian ini adalah berupa perencanaan Transfer Station (TS) berdasarkan kriteria yang dikemukakan oleh Tchobanoglous dkk. (1993) atau dalam regulasi di Indonesia (PerMen PU No. 13/2013) disebut dengan
Stasiun Peralihan Antara (SPA), yang mana SPA yang dikembangkan ini adalah SPA berskala kawasan yang merupakan pengembangan TPS Ciroyom eksisting yang berpotensi untuk ditingkatkan fungsinya.

Berdasarkan regulasi tersebut, SPA adalah sarana pemindahan dari alat angkut kecil ke alat angkut lebih besar, diperlukan untuk kabupaten/kota yang memiliki lokasi TPA yang jaraknya lebih dari $25 \mathrm{~km}$, dilengkapi dengan fasilitas reduksi volume sampah dengan proses pemadatan sampah, fasilitas ini dikelola oleh institusi pengelola sampah kota. Untuk meningkatkan efisiensi dan efektivitas pengelolaan sampah di wilayah layanan TPS Ciroyom, maka TPS konvensional eksisting direncanakan untuk dirancang ulang menjadi SPA yang mengandalkan pemadatan (kompaksi) sampah sehingga ritasi pengangkutan sampah ke TPA dapat dikurangi.

Kriteria teknis TPS dan SPA sesuai dengan yang tercantum pada PerMen PU No. 3/2013 dan PerMendagri No. 33/2010. TPS Ciroyom terletak di Kelurahan Ciroyom, Kecamatan Andir, Kota Bandung. Untuk saat ini TPS Ciroyom hanya berfungsi sebagai sarana penampungan sementara untuk sampah yang berasal dari sumber permukiman dan Pasar Ciroyom. Beban daerah pelayanan di TPS 
Widyarsana \& Daniel | Peningkatan Kapasitas TPS Ciroyom menjadi Stasiun Peralihan Antara (SPA) Berskala Kawasan di Kecamatan Andir, Kota Bandung Cantilever | Volume: 9 | Nomor: $1 \mid$ April 2020 | Hal. 25-32 | ISSN: 1907-4247 (Print) | ISSN: 2477-4863 (Online) | Website: http://cantilever.id

Ciroyom mencakup hampir seluruh Kecamatan Andir yaitu sebanyak 5 (lima) kelurahan dengan 75.877 jiwa beserta timbulan sampah yang berasal dari Pasar Ciroyom. Hal tersebut menimbulkan cukup besarnya volume sampah yang harus diangkut dari TPS ke TPA yang dapat mencapai 12 atau lebih ritasi/hari. Jarak dari TPS Ciroyom ke TPA Regional, Sarimukti yang mencapai $44 \mathrm{~km}$ menjadi pertimbangan utama dibutuhkannya fasilitas SPA di kawasan tersebut.

Fasilitas utama yang akan dirancang di SPA Ciroyom Berskala Kawasan berupa unit pemadatan sampah dengan metode vertical compression yang mampu mereduksi volume sampah yang tergolong residu sebesar 60-70\% (Takaendengan, 2017). Kehadiran SPA di kawasan tersebut diharapkan dapat mengurangi ritasi pengangkutan sampah ke Tempat Pemrosesan Akhir (TPA) beserta menjadi solusi dari permasalahan pengelolaan persampahan yang ada.

\section{METODOLOGI}

Pendekatan metodologi dalam penelitian ini, dapat dijelaskan dalam tahapan penelitian sebagai berikut:

a. Tahapan Studi Literatur

Tahapan pertama yang dilakukan adalah melakukan studi literatur sesuai dengan tema dan judul penelitian yang dipilih sebagai dasar dari pengambilan data, perencanaan, analisis, perhitungan maupun desain dari fasilitas yang akan direncanakan. Kemudian dilakukan pengambilan data berupa data primer dan data sekunder.

\section{b. Tahap Pengumpulan Data}

Pengumpulan data primer dilakukan dengan metode sampling untuk mengetahui jumlah timbulan, komposisi, densitas dan karakteristik sampah. Pengambilan data primer mengacu pada SNI 193964-1994 yang dilakukan di TPS Ciroyom untuk menghitung timbulan sampah yang berasal dari kategori permukiman di Pasar Ciroyom untuk menghitung timbulan sampah yang berasal dari nonpermukiman. Selain itu data primer dilakukan untuk mengetahui kondisi eksisting pengelolaan sampah yang sudah diterapkan melalui observasi dan wawancara. Data sekunder digunakan sebagai referensi perancangan SPA Berskala Kawasan yang didapatkan melalui berbagai literatur, peraturan yang berlaku, serta data-data yang relevan untuk proses perancangan dari dinas terkait.

\section{c. Tahap Evaluasi Kelayakan Kondisi Eksisting}

Tahapan selanjutnya adalah melakukan evaluasi kelayakan kondisi eksiting berdasarkan data primer maupun data sekunder yang sudah didapatkan. Hasil evaluasi merupakan dasar dalam perencanaan alternatif konsep pengembangan dan rencana daerah pelayanan SPA Berskala Kawasan.

\section{d. Tahap Pengembangan Konsep}

Kemudian ditentukan konsep pengembangan yang disesuaikan dengan Rencana Induk Persampahan Kota Bandung dilanjutkan dengan penentuan ruang lingkup pelayanan serta proyeksi penduduk untuk tahun yang direncanakan. Setelah itu dilakukan estimasi timbulan sampah menggunakan asumsi yang mempengaruhi laju timbulan sampah sehingga dapat menjadi dasar perhitungan kapasitas desain maksimum dari sistem yang dirancang. Kemudian dilakukan penentuan skenario sistem pengolahan sampah mulai dari input sistem sampai output fasilitas yang direncanakan melalui unit-unit pengolahan yang terpilih.

\section{e. Tahap Perancangan Teknis}

Tahap berikutnya yaitu melakukan perhitungan teknis untuk menentukan dimensi dan tata letak perancangan layout yang disesuaikan pula dengan ketersediaan lahan serta kemudahan operasional fasilitas yang direncanakan. Kemudian dilanjutkan dengan menggambar desain fasilitas.

\section{HASIL DAN PEMBAHASAN}

\subsection{Kondisi Eksisting Pengelolaan Sampah di TPS Ciroyom}

\subsubsection{Aspek Institusional dan Pelayanan}

Pengelolaan sampah khususnya sampah yang berasal dari masyarakat secara langsung seperti sampah permukiman dan sejenis permukiman dikelola oleh PD Kebersihan Kota Bandung. Namun PD Kebersihan Kota Bandung tidak bertanggung jawab terhadap semua tahapan pengelolaan persampahan melainkan hanya pada saat pemindahan, pengangkutan, dan TPA (PD Kebersihan Kota Bandung, 2016). Pewadahan dilakukan oleh pihak penghasil sampah itu sendiri, sedangkan pengumpulan dilakukan oleh petugas kebersihan yang biasanya dikelola oleh RW setempat. TPS Ciroyom merupakan salah satu TPS yang dikelola oleh PD Kebersihan Kota Bandung untuk wilayah operasional Bandung Barat (PD Kebersihan Kota Bandung, 2016).

TPS Ciroyom sendiri melayani sampah yang berasal dari 5 (lima) kelurahan di Kecamatan Andir yaitu Kelurahan Ciroyom, Dunguscariang, Garuda, Maleber dan 3 (tiga) RW di Kelurahan Campaka. Selain itu TPS Ciroyom juga menampung sampah dari Pasar Ciroyom. Untuk pengelolaan sampah yang berasal dari Pasar Ciroyom dilakukan oleh PT Anugrah Parahyangan Jaya yang bertugas untuk memonitor keberjalanan petugas pengumpul sampah untuk mengumpulkan dan mengangkut seluruh sampah dari setiap lapak/kios ke TPS Ciroyom. 


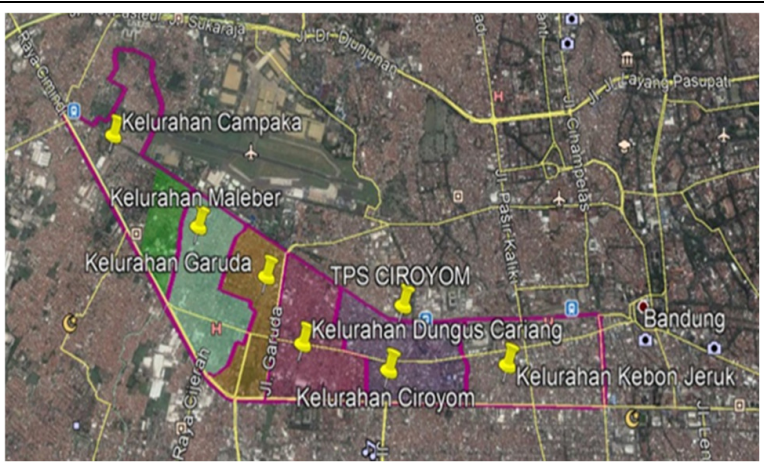

Gambar 1. Peta Daerah Pelayanan TPS Ciroyom (Sumber: Peta dimodifikasi dari Google Earth Pro, 2019)

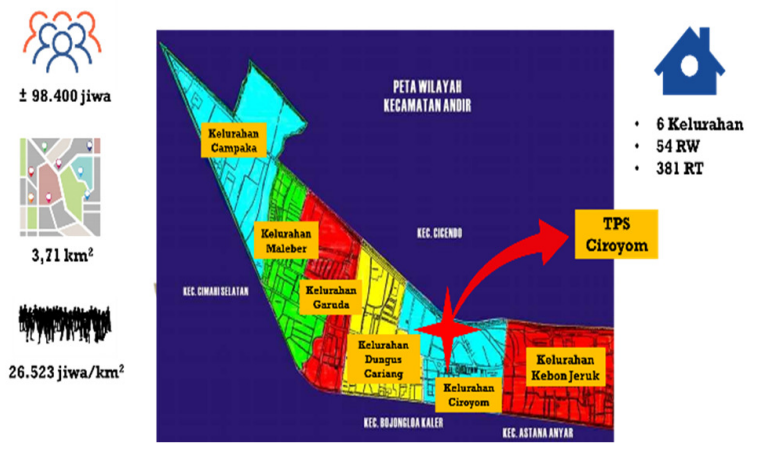

Gambar 2. Peta Wilayah Kecamatan Andir, Kota Bandung (Sumber: Peta dimodifikasi dari PT. Anugrah Parahyangan Jaya, 2019)

\subsubsection{Permasalahan Sistem}

Permasalahan pengelolaan sampah di TPS Ciroyom adalah tingginya angka timbulan sampah yang masuk ke TPS Ciroyom tanpa adanya pengolahan yang terjadi di dalamnya yang mengakibatkan seluruh sampah harus berakhir ke TPA dengan jumlah pengangkutan yang tidak sedikit. Penanganan sampah di TPS yang belum optimal seperti minimnya tingkat pemilahan sampah akibat kondisi sampah yang tercampur serta pengolahan sampah organik berupa biodigester yang sudah tidak berjalan pun menjadi faktor penyebab besarnya timbulan sampah tersebut.

Selain itu kondisi TPS Ciroyom yang tidak memiliki atap yang layak menyebabkan area TPS menjadi becek sehingga sampah banyak yang tergenang sehingga timbul lindi dan menimbulkan bau tidak sedap. Lindi yang tidak ditangani tersebut dapat menggangu kenyamanan dan keindahan di sekitar kawasan TPS Ciroyom bahkan dapat menjadi media penyebar mikroba patogen serta sarang vektor penyakit yang bisa mengancam kondisi lingkungan dan manusia.

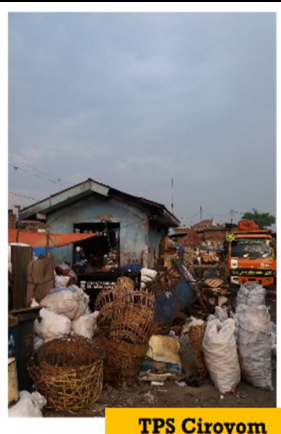

Kelurahan Ciroyom, Kecamatan Andir,

Kota Bandung

TPS Ciroyom
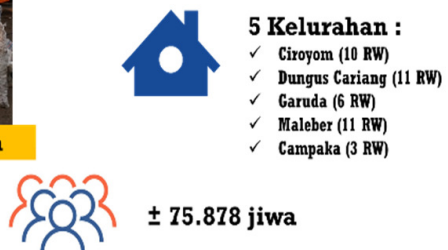

\pm 75.878 jiwa

Gambar 3. Kondisi Eksiting TPS Ciroyom di Kelurahan Ciroyom, Kecamatan Andir, Kota Bandung

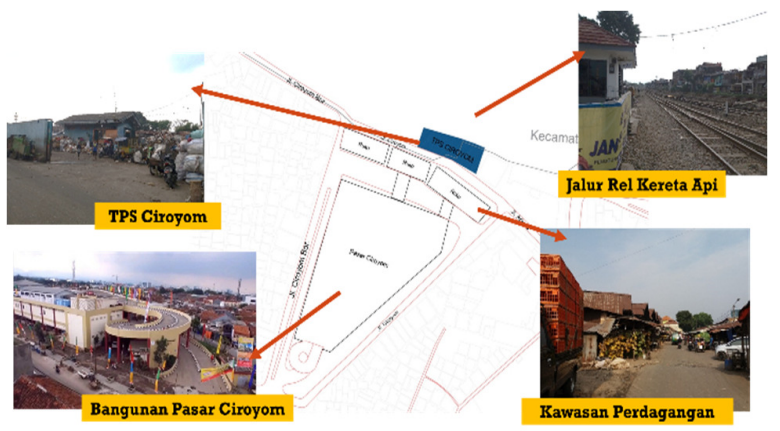

Gambar 4. Potret TPS Ciroyom dan Sekitarnya (Sumber: Peta dimodifikasi dari Google Maps, 2019)

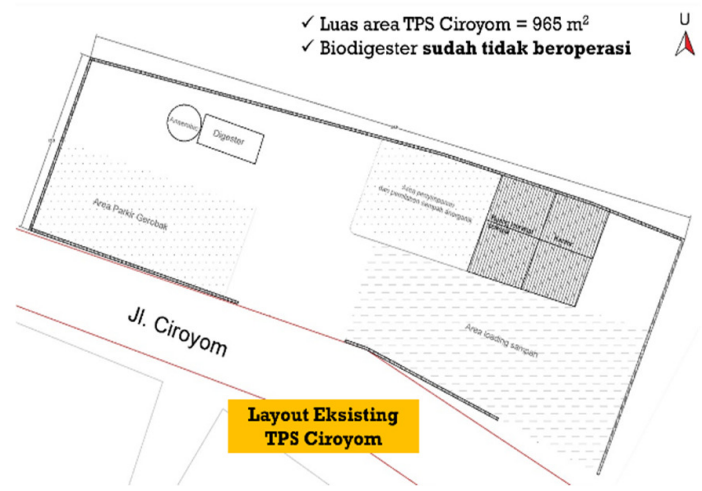

Gambar 5. Layout Eksisting TPS Ciroyom (Sumber: Peta dimodifikasi dari Google Maps, 2019)

\subsubsection{Timbulan dan Komposisi}

Berdasarkan hasil sampling di TPS Ciroyom diperoleh data timbulan sebesar $0,576 \mathrm{~kg} /$ orang/hari yang mewakili seluruh sumber permukiman dan 1,574 $\mathrm{kg} /$ pedagang/hari atau 1,64 ton/hari untuk timbulan yang berasal dari sumber Pasar Ciroyom, sedangkan komposisi sampah yang diperoleh berdasarkan hasil sampling ditunjukkan pada Gambar 6 di bawah ini. 


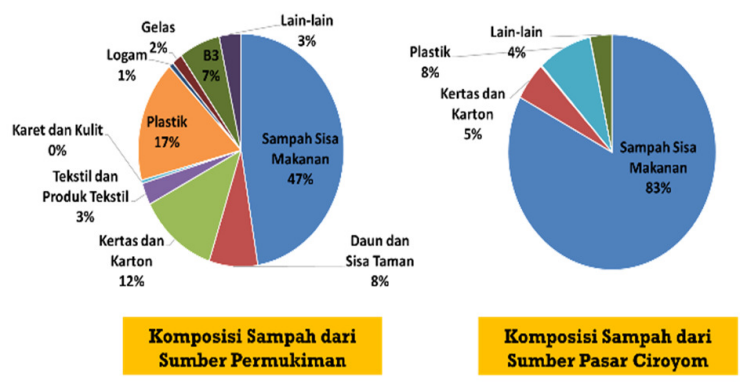

Gambar 6. Komposisi Sampah di TPS Ciroyom dari Sumber Permukiman dan Sumber Pasar Ciroyom

Dari hasil sampling komposisi sampah di kedua lokasi dapat disimpulkan bahwa sampah organik merupakan jenis sampah yang mendominasi. Namun persentase sampah organik berupa sampah sisa makanan di Pasar Ciroyom memiliki persentase yang lebih tinggi daripada sampah organik dari permukiman. Hal ini disebabkan karena Pasar Ciroyom merupakan pasar tradisional yang komoditas utamanya masih menjual bahan pangan dan sembako sehingga jenis sampah yang dihasilkan cenderung homogen, sedangkan sampah dari permukiman merupakan sampah yang lebih beragam jenisnya (heterogen). Sampah plastik memiliki persentase terbesar kedua baik yang berasal dari permukiman maupun Pasar Ciroyom, hal ini sangat menguntungkan dalam pengembangan circular economy yang menguntungkan masyarakat setempat (Widyarsana, 2019a).

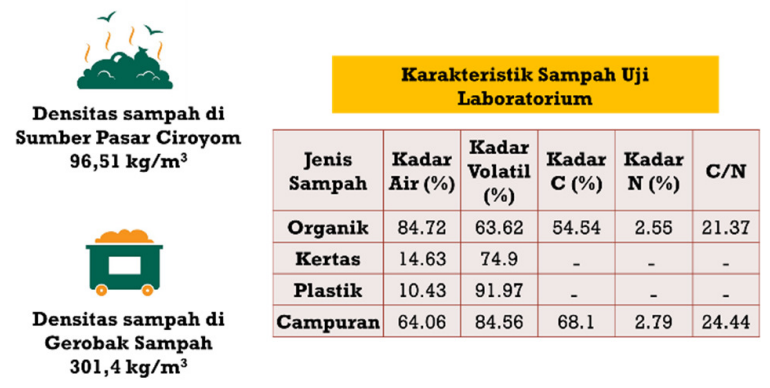

Gambar 7. Karakteristik Sampah TPS Ciroyom Berdasarkan Uji Laboratorium

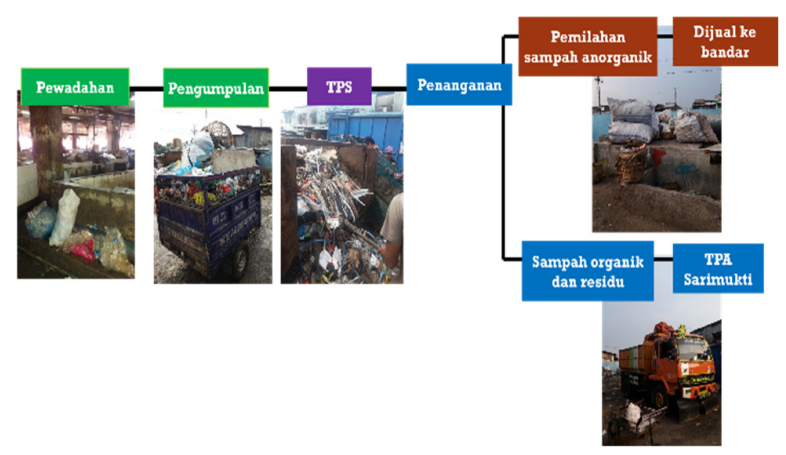

Gambar 8. Kondisi Eksiting Pengelolaan Sampah di TPS Ciroyom

\subsection{Hasil Perencanaan Pengembangan Sistem \\ Rencana Daerah Pelayanan Baru}

SPA Ciroyom Berskala Kawasan yang direncanakan hanya akan melayani permukiman yang ada di Kecamatan Andir saja seperti kondisi eksisting. Namun berdasarkan analisis proyeksi timbulan sampah berdasarkan data kependudukan dan proyeksi penduduk eksisting (BPS Kota Bandung, 2017a) serta mengacu kepada kriteria layanan yang diatur dalam PerMen PU No. 3/2013 maka SPA Berskala Kawasan hanya mampu menampung sampah dengan kapasitas mencapai 2030 ton/hari dalam radius area pelayanan $1,1-1,4 \mathrm{~km}$. Melalui hasil proyeksi timbulan sampah pada tahun 2031 didapatkan timbulan sebesar 57,85 ton/hari. Oleh karena itu dilakukan pembatasan area yang akan dilayani di Kecamatan Andir supaya SPA berskala kawasan dapat berjalan dengan optimal sesuai kapasitasnya. Setelah dilakukan pembatasan mengikuti radius area layanan yang disyaratkan maka didapatkan 3 (tiga) kelurahan yang akan dilayani yaitu Kelurahan Ciroyom, Dunguscariang, dan Garuda (BPS Kota Bandung, 2017b).

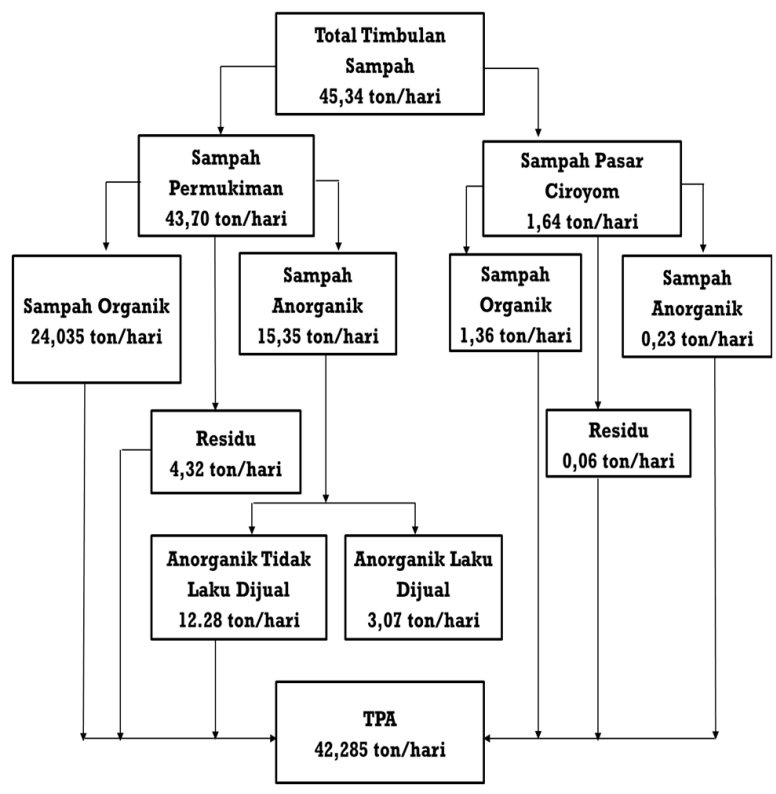

Gambar 9. Neraca Masa Eksisting Pengelolaan Sampah di Wilayah Pelayanan TPS Ciroyom

Dengan mengambil daerah layanan pengumpulan yang baru dapat dilakukan perhitungan kapasitas desain SPA Ciroyom lebih lanjut yang didasarkan pada proyeksi timbulan sampah masuk dengan jumlah penduduk yang baru. Untuk Kelurahan Maleber beserta 3 RW di Kelurahan Campaka yang tidak terlayani diasumsikan akan segera mempunyai TPS baru yang akan dibangun oleh Pemerintah Kota Bandung dalam waktu dekat. Hal tersebut sesuai dengan Rencana Induk Persampahan Kota Bandung Tahun 2017-2037 (DLH Kota Bandung, 2017). 


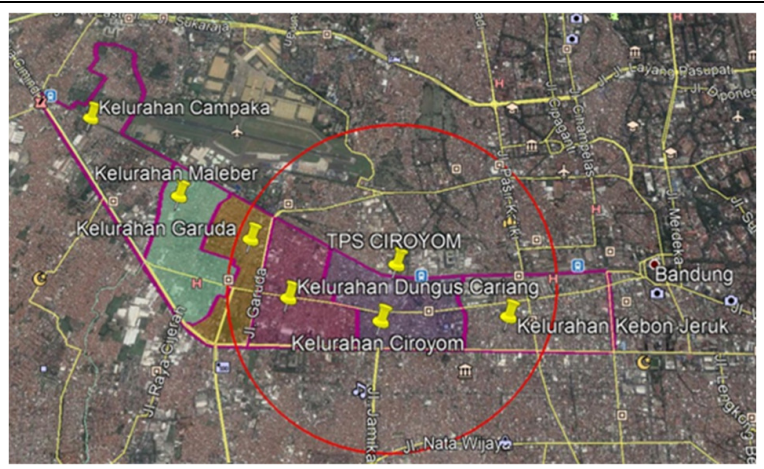

Gambar 10. Peta Daerah Pelayanan Baru Rencana SPA Ciroyom Berskala Kawasan

Tabel 1. Proyeksi Penduduk Daerah Pelayanan dengan Metode Logaritmik

\begin{tabular}{ccc}
\hline Tahun & $\begin{array}{c}\text { Jumlah Penduduk } \\
\text { Terlayani TPS Eksisting } \\
\text { (jiwa) }\end{array}$ & $\begin{array}{c}\text { Jumlah Penduduk } \\
\text { Rencana Terlayani SPA } \\
\text { (jiwa) }\end{array}$ \\
\hline 2019 & 78.945 & 46.474 \\
2020 & 79.337 & 46.592 \\
2021 & 79.692 & 46.700 \\
2022 & 80.017 & 46.798 \\
2023 & 80.315 & 46.888 \\
2024 & 80.591 & 46.971 \\
2025 & 80.848 & 47.049 \\
2026 & 81.089 & 47.121 \\
2027 & 81.315 & 47.190 \\
2028 & 81.528 & 47.254 \\
2029 & 81.729 & 47.315 \\
2030 & 81.921 & 47.372 \\
2031 & 82.102 & 47.427 \\
\hline Sumber: BPS Kota Bandung, $2017 b$ &
\end{tabular}

Sumber: BPS Kota Bandung, 2017 b

\section{Proyeksi Timbulan Sampah}

SPA Ciroyom Berskala Kawasan akan melayani daerah pelayanan yang baru sesuai rencana pengembangan selama tahun perencanaan. Proyeksi penduduk dengan metode terpilih yaitu logaritmik untuk 10 tahun masa operasional terhitung sejak tahun 2021-2031. Didapatkan jumlah penduduk sebesar 47.427 jiwa pada tahun 2031. Proyeksi timbulan sampah dilakukan selama periode tersebut yang disusun menjadi 3 (tiga) alternatif skenario seperti pada Tabel 2.

Tabel 2. Deskripsi Skenario Alternatif Perencanaan

\begin{tabular}{lccc}
\hline \multicolumn{1}{c}{ Parameter } & Skenario 1 & Skenario 2 & Skenario 3 \\
\hline Persentase upaya & Konstan & Meningkat & Meningkat dari \\
minimasi sampah & $2 \%$ & dari $2 \%$ & $2 \%$ menjadi \\
di sumber & & menjadi $25 \%$ & $25 \%$ \\
\hline Persentase & Konstan di & Meningkat & Meningkat dari \\
layanan & dari $90 \%$ & $90 \%$ menjadi \\
pengumpulan & $90 \%$ & menjadi $100 \%$ & $100 \%$ \\
sampah & & & \\
\hline Fungsi Fasilitas & Sebagai & Sebagai SPA & Sebagai SPA \\
& TPS & Berskala & Berskala \\
& & Wilayah & Wilayah \\
\hline Pengolahan & Tidak ada & Pemadatan & Recovery \\
sampah di & & Sampah & Anorganik, \\
fasilitas & & Residu & Pengomposan \\
& & & Organik, \\
& & & Pemadatan \\
& & & Sampah \\
\hline
\end{tabular}

Pada Skenario 2, SPA yang hendak dibangun hanya memiliki fasilitas mesin pemadat sampah, sedangkan pada Skenario 3 SPA akan dilengkapi dengan mesin pemadat sampah, fasilitas pengolahan sampah organik berupa pengomposan dan recovery sampah anorganik.

Dari ketiga skenario, skenario yang terpilih adalah skenario nomor 3 karena merupakan skenario yang memberikan manfaat pengurangan sampah paling besar terhadap pengelolaan sampah khususnya di kawasan Kecamatan Andir. Dari perbandingan ketiga skenario berdasarkan setiap parameter, dapat dilihat bahwa Skenario 3 lebih unggul dibandingkan kedua skenario lainnya.

Dengan adanya pengolahan tersebut, volume timbulan sampah dapat dikurangi, sampah organik dapat diolah menjadi kompos, dan sampah anorganik akan direcovery untuk didaur ulang oleh pihak ketiga berupa sektor informal. Oleh karena itu, dipilih Skenario 3 sebagai skenario terpilih. Pada skenario ini masyarakat meningkatkan persentase minimasi sampah sebanyak 3\% setiap tahun hingga mencapai target yaitu sebesar $25 \%$ pada tahun 2027 dan tetap konstan hingga akhir masa perancangan yaitu tahun 2031.

Angka tersebut belum mencapai target yang ditetapkan Jakstranas (PerPres No. 97 Tahun 2017) dimana angka pengurangan sampah mencapai 30\% pada tahun 2025. Hal tersebut disebabkan oleh berbagai kendala teknis dan nonteknis sehingga masyarakat masih enggan meminimasi sampah langsung dari sumbernya, sedangkan tingkat minimasi sampah diasumsikan berasal dari meningkatnya kesadaran masyarakat akan timbulan sampah yang kian meningkat dan efektifnya program-program pemerintah Kota Bandung. Hal tersebut sesuai dengan program nyata Wali Kota Bandung periode 2018-2023, yaitu Kang Pisman yang merupakan singkatan dari Kurangi, Pisahkan, dan Manfaatkan. Pengelolaan sampah melalui upaya minimasi sampah di sumber akan ikut mengurangi timbulan sampah yang akan masuk ke SPA.

Persentase layanan yang tiap tahun meningkat akan membuat pengelolaan sampah kawasan pun semakin optimal. Selain itu pengolahan sampah seperti recovery anorganik dan pengomposan organik akan turut membantu mengurangi timbulan sampah yang akan dibawa ke TPA apabila hanya mengandalkan kegiatan pemadatan sampah saja. Setelah alternatif skenario terpilih maka selanjutnya ditentukan kapasitas desain maksimum yang diperlukan selama masa operasional. Kapasitas desain maksimum yang diperoleh yaitu sebesar 28 ton/hari yang digambarkan pada Gambar 11 . 
Widyarsana \& Daniel | Peningkatan Kapasitas TPS Ciroyom menjadi Stasiun Peralihan Antara (SPA) Berskala Kawasan di Kecamatan Andir, Kota Bandung Cantilever | Volume: 9 | Nomor: 1 | April 2020 | Hal. 25-32 | ISSN: 1907-4247 (Print) | ISSN: 2477-4863 (Online) | Website: http://cantilever.id

Tabel 3. Proyeksi Timbulan Sampah Daerah Pelayanan Baru

\begin{tabular}{|c|c|c|c|c|c|c|c|}
\hline \multirow{3}{*}{ Tahun } & \multicolumn{2}{|c|}{ Total Timbulan Sampah } & \multirow{3}{*}{$\begin{array}{l}\text { Reduksi di } \\
\text { Sumber (\%) }\end{array}$} & \multirow{3}{*}{$\begin{array}{l}\text { Pelayanan } \\
\text { Pengumpulan } \\
(\%)\end{array}$} & \multirow{2}{*}{\multicolumn{2}{|c|}{$\begin{array}{l}\text { Timbulan Sampah Terangkut } \\
\text { ke TPS }\end{array}$}} & \multirow{3}{*}{$\begin{array}{c}\begin{array}{c}\text { Kapasitas Maksimum SPA } \\
\text { Kawasan } \\
\text { (PerMen PU No. 3/13) }\end{array} \\
\text { (ton hari) }\end{array}$} \\
\hline & \multirow{2}{*}{ (mhari) } & \multirow{2}{*}{ (ton hari) } & & & & & \\
\hline & & & & & (mhari) & (ton/hari) & \\
\hline 2019 & 154,66 & 29,53 & 2,00 & 90,00 & 136,41 & 26,04 & 30 \\
\hline 2020 & 156,70 & 29,24 & 5,00 & 91,00 & 135,46 & 25,28 & 30 \\
\hline 2021 & 158,72 & 29,62 & 8,00 & 92,00 & 134,34 & 25,07 & 30 \\
\hline 2022 & 160,73 & 29,99 & 11,00 & 93,00 & 133,04 & 24,83 & 30 \\
\hline 2023 & 162,75 & 30,37 & 14,00 & 94,00 & 131,56 & 24,55 & 30 \\
\hline 2024 & 164,76 & 30,75 & 17,00 & 95,00 & 129,91 & 24,24 & 30 \\
\hline 2025 & 166,78 & 31,12 & 20,00 & 96,00 & 128,09 & 23,90 & 30 \\
\hline 2026 & 168,80 & 31,50 & 23,00 & 97,00 & 126,08 & 23,53 & 30 \\
\hline 2027 & 170,84 & 31,88 & 25,00 & 98,00 & 125,57 & 23,43 & 30 \\
\hline 2028 & 172,88 & 32.26 & 25,00 & 99,00 & 128.36 & 23.95 & 30 \\
\hline 2029 & 174,93 & 32,64 & 25,00 & 100,00 & 131,20 & 24,48 & 30 \\
\hline 2030 & 177,00 & 33,03 & 25,00 & 100,00 & 132,75 & 24,77 & 30 \\
\hline 2031 & 179,08 & 33,42 & 25,00 & 100,00 & 134,31 & 25,06 & 30 \\
\hline
\end{tabular}

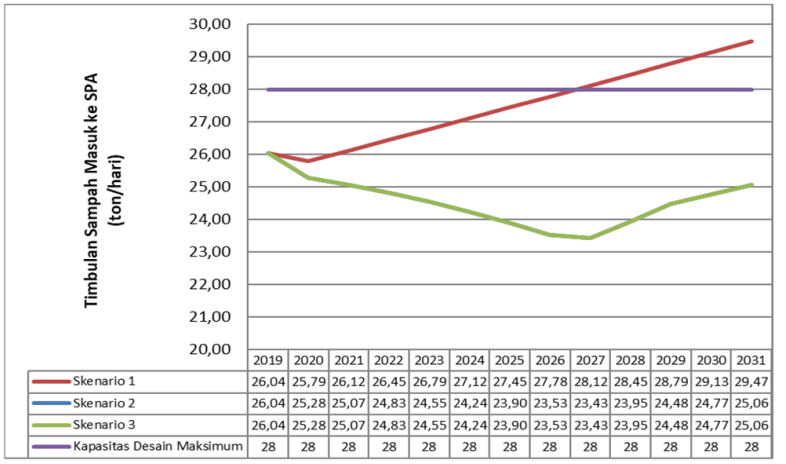

Gambar 11. Skenario Timbulan Sampah dan Kapasitas Desain Maksimum

\section{Penanganan Sampah}

SPA Ciroyom Berskala Kawasan yang akan dirancang akan memiliki fasilitas utama pengolahan sampah berupa unit pemadat sampah. Namun sesuai skenario yang telah dipilih sampah yang masuk akan melalui berbagai kegiatan penanganan sampah terlebih dahulu. Sampah yang masuk ke SPA akan dipilah secara manual di SPA menggunakan conveyor belt. Pemilahan ini akan memisahkan sampah tercampur ke dalam berbagai jenis sampah sehingga memudahkan pengolahan sampah menurut jenisnya. Sampah organik yang berhasil dipilah akan melalui tahap pengolahan yaitu pengomposan. Dalam penentuan alternatif teknologi pengomposan sampah yang tepat maka dilakukan pembobotan dengan mempertimbangkan aspek ekonomi, kebutuhan lahan, teknologi, sosial maupun lingkungan. Sistem pengolahan biologis dengan komposting open windrow (SNI 19-2454-2002) merupakan teknologi terpilih berdasarkan hasil pembobotan. Sampah anorganik yang sudah terpilah juga kemudian akan dikelompokkan berdasarkan jenisnya yaitu kertas dan karton, plastik HDPE dan LDPE, logam dan kaca untuk dijual dan dikelola selanjutnya pada pihak ketiga untuk didaur ulang dalam skema circular economy (Widyarsana, 2019a). Selain itu sampah anorganik yang berpotensi digunakan ulang akan diserahkan melalui sektor informal untuk memanfaatkan sampah tersebut sebagai bahan kerajinan untuk ditingkatkan nilai gunanya, opsi ini juga merupakan lingkup kegiatan circular economy.

Tabel 4. Pemilihan Alternatif Pengolahan Sampah Organik

\begin{tabular}{|c|c|c|c|c|c|c|c|c|}
\hline \multirow[t]{2}{*}{ Parameter } & \multirow[t]{2}{*}{ Subparameter } & \multirow[t]{2}{*}{$\%$} & \multicolumn{2}{|c|}{ Windrow } & \multicolumn{2}{|c|}{ Caspary } & \multicolumn{2}{|c|}{ Fixed-Dome Digester } \\
\hline & & & Nilai & Hasil & Nilai & Hasil & Nilai & Hasil \\
\hline \multirow[t]{2}{*}{ Ekonomi } & Biaya Investasi & $13 \%$ & 1 & 0.13 & 2 & 0.07 & 3 & 0.04 \\
\hline & $\begin{array}{l}\text { Biaya operasional dan } \\
\text { pemeliharaan }\end{array}$ & $17 \%$ & 1 & 0.17 & 2 & 0.09 & 3 & 0.06 \\
\hline \multicolumn{2}{|c|}{ Kebutuhan Lahan } & $20 \%$ & 3 & 0.07 & 2 & 0.10 & 1 & 0.20 \\
\hline Sosial & $\begin{array}{l}\text { Meningkatkan kesempatan } \\
\text { kerja }\end{array}$ & $10 \%$ & 2 & 0.07 & 2 & 0.07 & 3 & 0.04 \\
\hline \multirow[t]{3}{*}{ Teknologi } & Pengendalian proses & $5 \%$ & 1 & 0.05 & 2 & 0.03 & 2 & 0.03 \\
\hline & Waktu proses & $5 \%$ & 3 & 0.02 & 3 & 0.02 & 1 & 0.05 \\
\hline & $\begin{array}{l}\text { Kemudahan operasional } \\
\text { dan pemeliharaan }\end{array}$ & $10 \%$ & 1 & 0.10 & 2 & 0.05 & 3 & 0.03 \\
\hline \multirow[t]{2}{*}{ Lingkungan } & Bau & $10 \%$ & 3 & 0.03 & 3 & 0.03 & 2 & 0.05 \\
\hline & Kualitas Lindi & $10 \%$ & 3 & 0.03 & 3 & 0.03 & 1 & 0.10 \\
\hline \multicolumn{3}{|c|}{ Total } & & 0.67 & & 0.47 & & 0.60 \\
\hline
\end{tabular}

Tabel 5. Perbandingan Kondisi Eksisting TPS Ciroyom dengan Kriteria Teknis SPA Kawasan

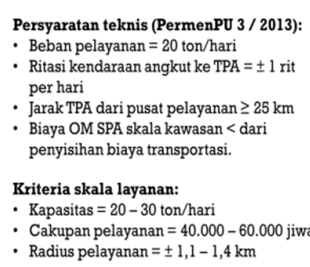

\begin{tabular}{|c|c|c|}
\hline Kriteria & Kondisi Eksisting & Status \\
\hline Luas SPA paling sedikit $600 \mathrm{~m}^{2}$ & $\begin{array}{l}\text { Luas TPS Ciroyom = } \\
965 \mathrm{~m}^{2}\end{array}$ & Terpenuhi \\
\hline $\begin{array}{l}\text { Produksi timbulan sampah } \\
20-30 \text { ton/hari }\end{array}$ & $\begin{array}{l}\text { Estimasi timbulan } \\
\text { sampah }=45,34 \\
\text { ton/hari }\end{array}$ & $\begin{array}{l}\text { Terpenuhi } \\
\text { (melebihi } \\
\text { kriteria) }\end{array}$ \\
\hline $\begin{array}{l}\text { Lokasi penempatan SPA di titik } \\
\text { pusat area lingkungan hunian }\end{array}$ & $\begin{array}{l}\text { Terletak di sekitar } \\
\text { daerah hunian }\end{array}$ & Terpenuhi \\
\hline $\begin{array}{l}\text { Fasilitas SPA dilengkapi dengan } \\
\text { ramp, sarana pemadatan, dan } \\
\text { penampungan lindi }\end{array}$ & Belum tersedia & $\begin{array}{c}\text { Belum } \\
\text { Terpenuhi }\end{array}$ \\
\hline $\begin{array}{l}\text { Pengolahan lindi dapat } \\
\text { dilakukan di SPA atau TPA }\end{array}$ & Belum tersedia & $\begin{array}{c}\text { Belum } \\
\text { Terpenuhi }\end{array}$ \\
\hline
\end{tabular}

Sampah yang tersisa dan tidak laku dijual akan masuk ke area pemadatan dan digolongkan sebagai residu untuk diangkut menuju TPA. TPA merupakan alternatif terakhir dalam penanganan sampah yang sangat berpotensi menimbulan resiko negatif (Widyarsana, 2019b). Begitu pula untuk sampah B3 rumah tangga yang sudah dipilah akan ditangani dengan dipisahkan secara khusus dalam area penyimpanan sebelum diambil oleh pihak ketiga yang mempunyai kapasitas untuk melakukan pengolahan lebih lanjut. Untuk mempermudah alur sistem penanganan sampah yang akan dilakukan di SPA Ciroyom Berskala Kawasan maka dibuat neraca massa aliran sampah yang ditunjukkan pada Gambar 13. Penyusunan neraca masa tersebut mencontoh metode yang dikembangkan oleh Widyarsana, dkk (2020a).

\section{Desain SPA Ciroyom Berskala Kawasan}

Luas yang dimiliki oleh TPS Ciroyom sebagai lokasi perencanaan SPA yaitu sebesar 962,4 $\mathrm{m}^{2}$. Luas area yang dibutuhkan untuk masing-masing kegiatan penanganan sampah ditentukan melalui perhitungan sampah yang akan masuk beserta ketersediaan lahan yang ada sehingga diperoleh perkiraan luas penggunaan lahan yang ditunjukan pada Tabel 6 . Hasil rancangan SPA Ciroyom Berskala Kawasan berupa layout dapat dilihat pada Gambar 14. 
Cantilever | Volume: 9 | Nomor: 1 | April 2020 | ISSN: 1907-4247 (Print) | ISSN: 2477-4863 (Online) | Website: http://cantilever.id

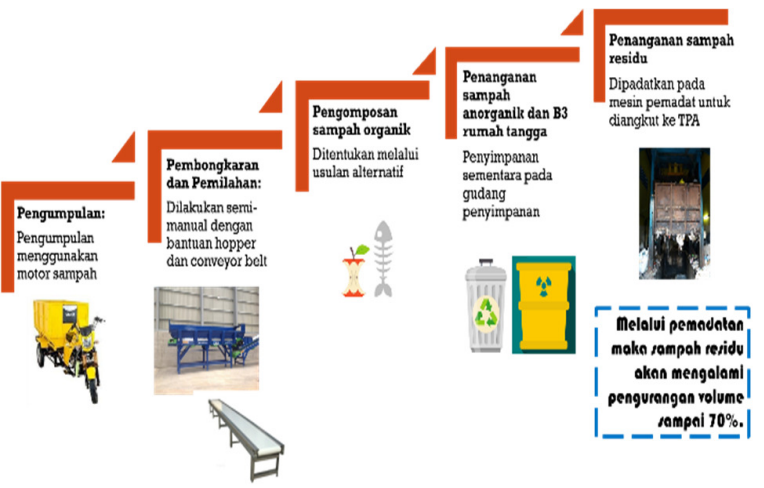

Gambar 12. Usulan Penanganan Sampah di SPA Ciroyom Berskala Kawasan
Tabel 6. Kebutuhan Lahan Fasilitas SPA Ciroyom Berskala Kawasan

\begin{tabular}{lc}
\multicolumn{1}{c}{ Fasilitas } & Luas $\mathbf{( m}^{\mathbf{2}} \mathbf{~}$ \\
\hline Area Bongkar Muat (Unloading Area) & 30 \\
Area Prapemilahan (Presorting Area) & 30 \\
Area Pemilahan (Sorting Area) & 66,5 \\
Gudang Sampah Anorganik (Plastik, Kertas, & 44 \\
Logam, Kaca) & \\
Gudang Sampah B3 & 10 \\
Area Pengomposan & 245 \\
Gudang Penyimpanan Kompos & 57 \\
Ruang Pemadatan Sampah & 70 \\
Bak Penampung Lindi & 1 \\
Area Pengangkutan (Loading Area) & 30 \\
Kantor Administrasi & 9 \\
Ruang Pekerja dan Ruang Kesehatan & 12 \\
Pos Jaga & 8 \\
Toilet & 15,75 \\
Septic Tank & 2 \\
\hline \multicolumn{2}{c}{ Total }
\end{tabular}

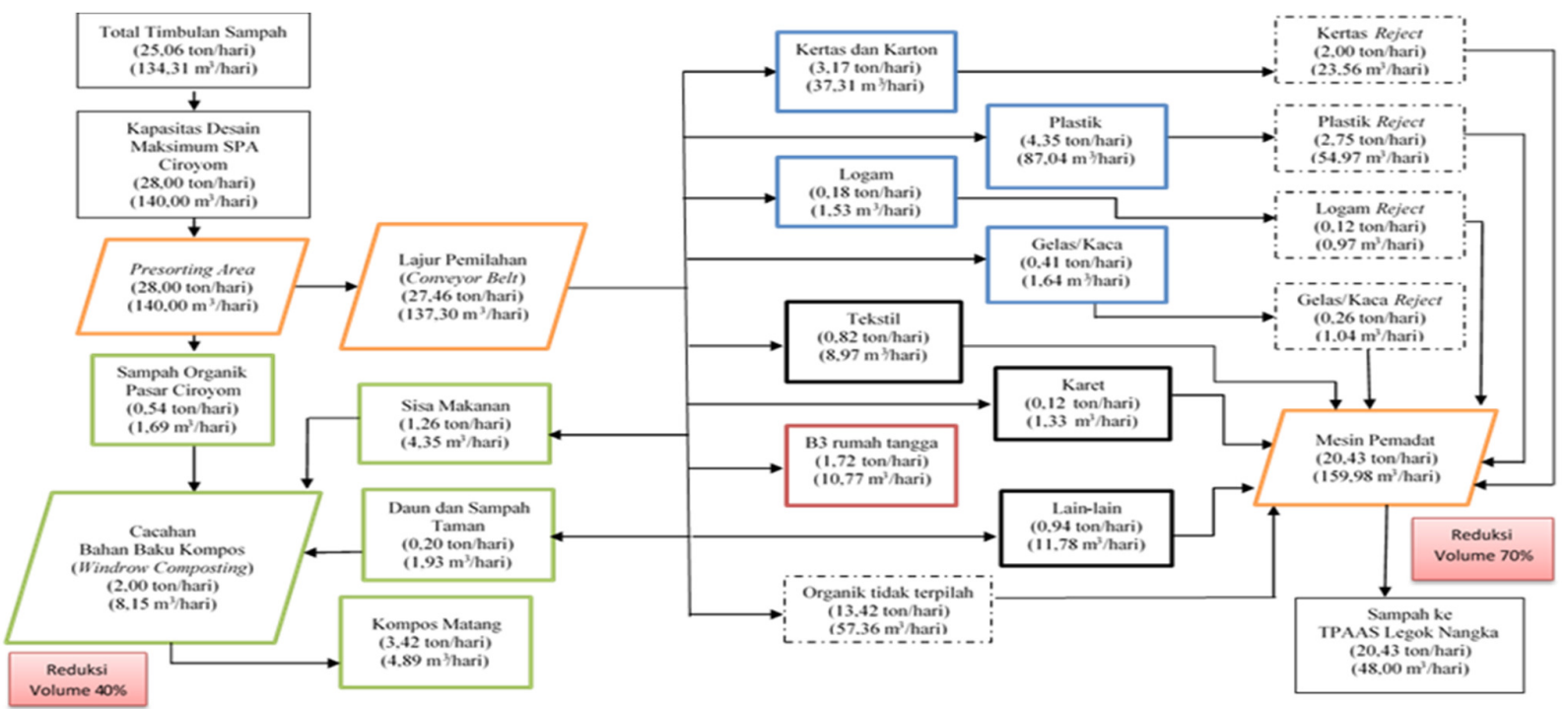

Gambar 13. Neraca Massa Aliran Sampah Rencana SPA Ciroyom Berskala Kawasan

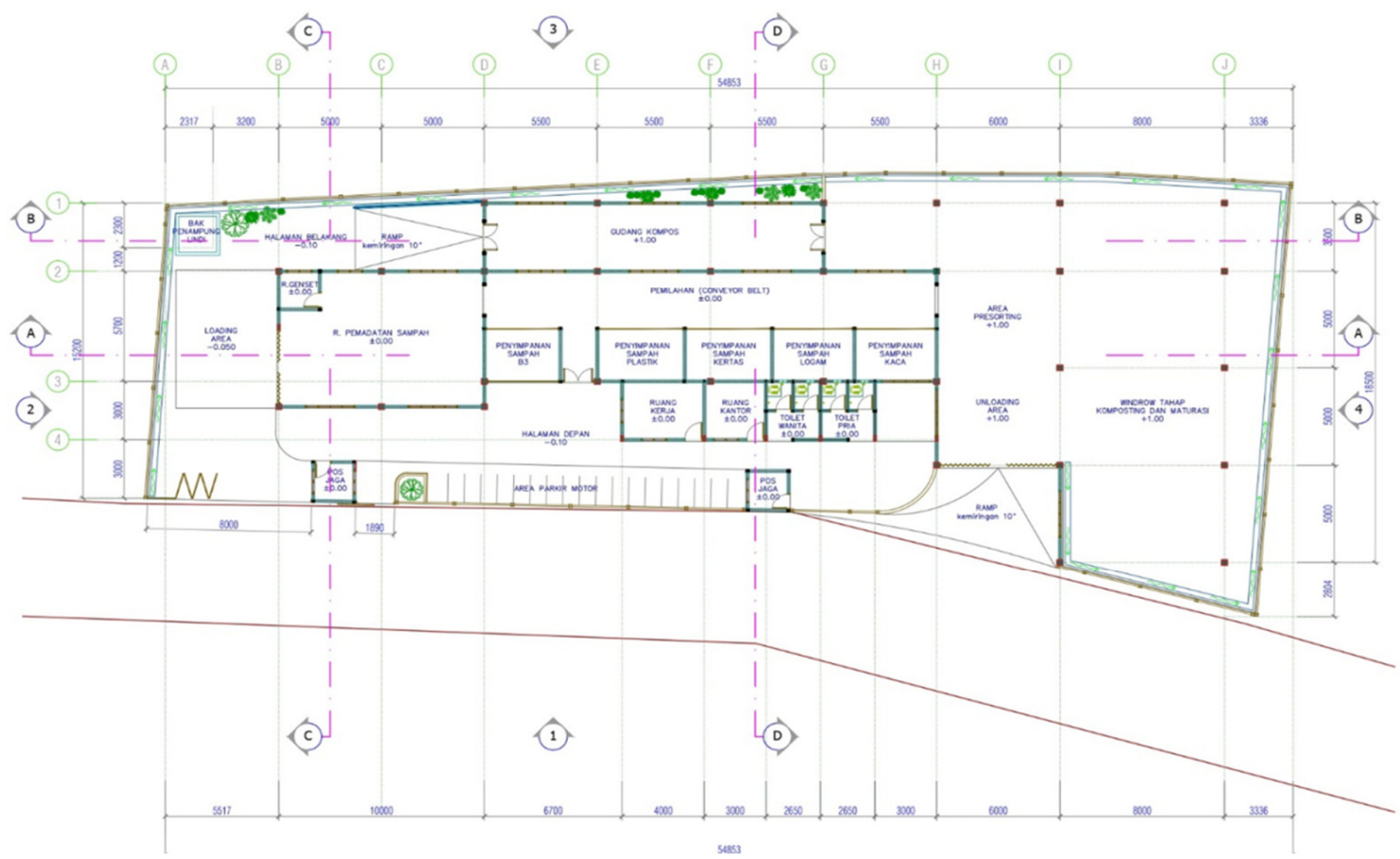

Gambar 14. Layout Perencanaan SPA Ciroyom Berskala Kawasan 


\section{KESIMPULAN}

TPS Ciroyom merupakan salah satu fasilitas persampahan yang ada di Kecamatan Andir. TPS Ciroyom dikelola oleh PD Kebersihan Kota Bandung yang memiliki fungsi sebagai sarana penampungan sementara untuk sampah yang berasal dari sumber permukiman dan sampah dari Pasar Ciroyom. Besarnya daerah pelayanan TPS Ciroyom yang hampir mencapai satu kecamatan, yaitu 5 (lima) dari 6 (enam) kelurahan membuat beban timbulan sampah yang masuk sangat besar yaitu mencapai 158,39 $\mathrm{m}^{3} /$ hari. Hal tersebut membuat banyaknya jumlah pengangkutan sampah dari TPS ke TPA yang mencapai 12 ritasi/hari. Jarak dari TPS Ciroyom ke TPA Sarimukti yang berkisar $44 \mathrm{~km}$ menjadi pertimbangan utama dibutuhkannya fasilitas Stasiun Peralihan Antara (SPA) Ciroyom di kawasan tersebut. SPA berperan dalam mereduksi volume sampah sehingga mampu mengurangi ritasi pengangkutan sampah ke Tempat Pemrosesan Akhir (TPA). Dengan luas lahan yang memadai, TPS Ciroyom memiliki potensi untuk ditingkatkan fungsinya menjadi SPA berskala kawasan. Fasilitas utama yang dirancang di SPA berskala kawasan Ciroyom adalah unit pemadatan sampah sehingga terjadi reduksi volume dengan metode vertical compression. Melalui pemadatan sampah, khususnya sampah yang tergolong residu diharapkan akan mengalami reduksi atau pengurangan volume sebesar $70 \%$. Melalui hasil proyeksi timbulan sampah pada tahun 2031 didapatkan timbulan sebesar 57,85 ton/hari. Kebutuhan lahan minimal fasilitas SPA Ciroyom berskala kawasan adalah sebesar $630,25 \mathrm{~m}^{2}$, dapat disimpulkan masih tercukupi dari luas lahan yang tersedia yaitu sebesar $965 \mathrm{~m}^{2}$.

\section{REFERENSI}

Badan Pusat Statistik Kota Bandung. (2017a). Kota Bandung dalam Angka Tahun 2017. Bandung: BPS Kota Bandung.

Badan Pusat Statistik Kota Bandung. (2017b). Kecamatan Andir dalam Angka Tahun 2017. Bandung: BPS Kota Bandung.

Badan Standardisasi Nasional Indonesia. (1994). SNI 19-39641994: Metode Pengambilan dan Pengukuran Contoh Timbulan dan Komposisi Sampah. Jakarta: BSNI.

Badan Standardisasi Nasional Indonesia. (2004). SNI 19-24542002 tentang Tata Cara Teknis Operasional Pengelolaan Sampah Perkotaan. Jakarta: BSNI.
Damanhuri, E., Widyarsana, I. M. W., Ramang, R., \& Padmi, T. (2009). Evaluation of Municipal Solid Waste Flow in the Bandung Metropolitan Area, Indonesia. J Mater Cycles Waste Management (2009), 11, pp. 270-276.

Damanhuri, E. (2008). Challenges of Municipal Solid Waste Management in Indonesia: Implications of the Solid Waste Act 18/2008. The International Conference 2008 - the Sustainable Environmental Technology and Sanitation for Tropical Region, ITS, Surabaya, 18 - 19 November 2008.

Dinas Lingkungan Hidup Kota Bandung. (2017). Rencana Induk Persampahan Kota Bandung Tahun 2017-2037. Bandung: DLH Kota Bandung.

PP No. 81 Tahun 2012. (2012). Pengelolaan Sampah Rumah Tangga dan Sampah Sejenis Sampah Rumah Tangga. Jakarta: Sekretariat Negara.

PD Kebersihan Kota Bandung. (2016). Pengelolaan Sampah di Kota Bandung. Bandung.

Peraturan Presiden Republik Indonesia No. 97 Tahun 2017. (2017). Kebijakan dan Strategi Nasional Pengelolaan Sampah Rumah Tangga dan Sampah Sejenis Sampah Rumah Tangga. Jakarta: Sekretariat Negara.

Peraturan Menteri PU No. 03 Tahun 2013. (2013). Penyelenggaran Prasarana dan Sarana Persampahan Dalam Penanganan Sampah Rumah Tangga dan Sampah Sejenis Sampah Rumah Tangga. Jakarta: Sekretariat Negara.

Peraturan Menteri Dalam Negeri No. 33 Tahun 2010. (2010). Pedoman Pengelolaan Sampah. Jakarta: Sekretariat Negara.

Takaendengan, T. (2017). Optimasi Skenario Sistem Pengangkutan Sampah Yang Terintegrasi Dengan Tempat Pemrosesan Akhir (TPA) Regional (Studi Kasus Kota Manado). Bandung: Institut Teknologi Bandung.

Tchobanoglous, G., Theisen, H., \& Vigil, S. A. (1993). Integrated Solid Waste Management. Mc Graw-Hill International Editions

Undang-Undang No. 18 Tahun 2008. (2008). Pengelolaan Sampah. Jakarta: Sekretariat Negara.

Widyarsana, I. M. W. (2019a). Circularity Tour Bali: Membangun Sistem Daur Ulang untuk Mewujudkan Bali yang Bersih. Materi Workshop Danone, Bali

Widyarsana, I. M. W., Damanhuri, E., Agustina, E., \& Nur Aulia, R. (2019b). Risk Assessment and Rehabilitation Potential of Municipal Solid Waste Landfills in Bali Province, Indonesia. International Journal of GEOMATE, 17(63), pp. $164-171$.

Widyarsana, I. M. W., Damanhuri, E., \& Agustina, E. (2020a). Municipal solid waste material flow in Bali Province, Indonesia. J Mater Cycles Waste Manag, 22(8), pp. 405415.

Widyarsana, I. M. W. \& Agustina, E. (2020b). Waste Management Study In The Archipelago Tourism Area (Case Study: Nusa Penida District, Bali Province, Indonesia). E3S Web of Conf., 148 (2020)05002. 